\title{
FORMULATION AND EVALUATION OF TETRACAINE HYDRO- CHLORIDE POLYMERIC FILMS FOR TOPICAL APPLICATION
}

\author{
A.E. Aboutaleb ${ }^{1}$, E.M. Samy ${ }^{1}$, Ahmed Ismail ${ }^{2}$ and M. Amin ${ }^{2}$ \\ ${ }^{1}$ Department of Industrial Pharmacy, Faculty of Pharmacy, Assiut University, Assiut \\ ${ }^{2}$ Department of Pharmaceutics and Industrial Pharmacy, Al-Azhar University, Assiut Branch, \\ Assiut
}

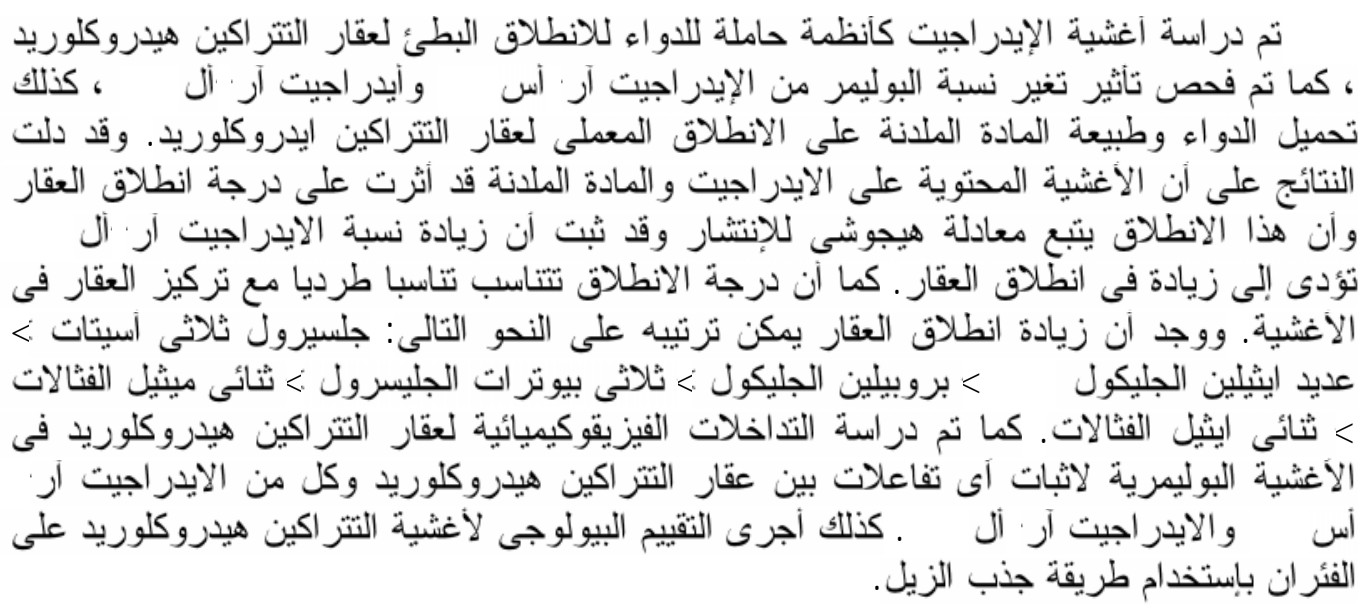

Eudragit polymeric films were investigated as a potential drug delivery system for controlling the release of tetracaine $\mathrm{HCl}$. The effect of modification in polymeric ratio of both Eudragit RS100 and RL100, drug loading and nature of plasticizer on the in vitro release of the drug from each film into a receiving medium of citrate buffer $(\mathrm{pH=5})$ was measured. The obtained results indicated that the film containing Eudragit polymer and plasticizer affected the drug release rate and that the release followed Higuchi-diffusion model. The release rate was found to be enhanced with increasing Eudragit RL100 ratio. The release rate was also found to be directly proportional to drug concentration. Tetracaine $\mathrm{HCl}$ was slowly released from Eudragit RS100 / dimethylphthalate films and Eudragit RS100 / diethyl-phthalate films. Eduragit films plasticized with GTA, PEG400 and PG produced a fast drug release. This study demonstrated that tetracaine $\mathrm{HCl}$ was compatible with Eudragit RS100 as indicated by the clear and transparent formed films. Also, the characterizations of Eudragit films were conducted by IR-spectroscopy, X-ray diffraction pattern and differential thermal analysis to explore the possibility of the drug polymer interaction occurring between tetracaine $\mathrm{HCl}$ and either Eudragit RS100 or Eudragit RL100. The therapeutic potential of tetracaine HCl Eudragit polymeric films was evaluated using "Tail-Flick" method on a Techano analyiseometer model. Results indicated that tetracaine HCL polymeric film composed of Eudragit RS100: Eudragit RL100 ratio (8:2) and plasticized with $20 \% \mathrm{w} / \mathrm{w}$ diethylphthalate gave a long duration of analgesic response.

\section{INTRODUCTION}

Incorporation of drugs in inert polymeric films during their manufacture affords a possible method of achieving controlled release. Such products can be adapted to topical, oral and other routes of administration by utilizing them directly or in the form of coatings. ${ }^{1-3}$

Eudragit RS is a copolymer synthesized from acrylic and methacrylic acid esters with low content of quaternary ammonium groups. Poly(meth)acrylates can be used in various ways to develop oral formulations with 
controlled release. ${ }^{4}$ This polymer is inert to the digestive tract, $\mathrm{pH}$ independant, impermeable to water, and capable of swelling and release of active ingredient by diffusion. The RL polymer contains a greater molar ratio of these ionizable groups, which causes it to be more permeable than the Eudragit RS. Plasticizers are usually added to polymeric films to enhance their flexibility and reduce their brittleness. ${ }^{5,6}$

Tetracaine $\mathrm{HCl}$ is a local anesthetic of ester type. It is applied topically to the eye to produce local anesthesia for tonometry, gonioscopy, removal of foreign bodies or sutures from the cornea and corneal scraping for diagnostic purposes. It has short duration of action, so frequent applications are usually required. So, it is preferable to formulate tetracaine $\mathrm{HCl}$ in polymeric films, which may control the drug delivery over a reasonable period of time.

The primary objective of this study was to study the effects of drug loading, nature of plasticizer and modification of the ratio of Eudragit RS100 to Eudragit RL100 on the release behavior. Also the possibility of drugpolymer interactions were conducted by DSC, $\mathrm{X}$-ray and IR studies to explore the drugpolymer compatibility. Finally the biolgical activity of tetracaine $\mathrm{HCl}$ Eudragit polymeric films was also studied.

\section{EXPERIMENTAL}

- Tetracaine $\mathrm{HCl}$ (Siegfried ZofingerSwizerland).

- Glycerol triacetate (GTA), diethylphthalate (DEPH), glycerol tributyrate (GTB) and dimethylphthalate (DMPH) (Merck, Suhuchardt, Munchen, W. Germany).

- Eudragit RS100 and RL100 (Rohm Pharma, GMBM Darmstadt, W. Germany).

- PEG400, propylene glycol (PG), citric acid and trisodium citrate (El-Nasr Company, Abou-Zabal, Egypt).

- Silicon adhesive (Super Automotive and Consumer Products Co., U.S.A.).

- Chloroform (El-Nasr Company, AbouZabal, Egypt).

\section{Equipment}

1- Electronic digital balance (Metler-Toledo, Ag, CH-8606, Greifensee, Swizerland).
2- Spectrophotometer U.V 1601 (Shimadzu Co., Japan).

3- Teflon plates

4- Dissolution-Test Apparatus, SR11 6 Flask (Hanson Research, USA).

5- IR-spectrophotometer, IR-476 (Shimadzu Co., Japan).

6- Differential Thermal Analysis, Shimadzu DTA-50, equipped with a Computerized Data Station (Shimadzu Co., Japan).

7- X-ray Diffractometer (Phillips Co., Netherlands).

8- Micrometer (Mitotoya, Japan).

\section{Film preparation}

Polymeric films were prepared using casting solvent technique where chloroform was poured into a teflon disc $\left(\operatorname{area}=28.26 \mathrm{~cm}^{3}\right)$ placed on a flat surface at room temperature. Tetracaine $\mathrm{HCl}$ and polymer (Eudragit RS100) or different ratios of Eudragit RS100 / Eudragit RL100) were accurately weighed and then dispersed in chloroform. The mixture was stirred until the polymer was dissolved and the solution was well mixed. Film solution was distributed and chloroform was allowed to be evaporated at room temperature. Complete evaporation was obtained by drying for $24 \mathrm{hrs}$ to a constant weight. These films were stored in a desiccator (containing anhydrous calcium chloride) for $24 \mathrm{hrs}$ and then placed in a sealed container until time of use. Eudragit RS100 films were prepared containing different concentrations of tetracaine $\mathrm{HCl}$, and the release profile for each film was examined. Eudragit RS100 films containing different types of plasticizers, GTA, GTB, DMPH, DEPH, PG and PEG400 were also prepared.

The thickness of the dried films was measured at five different places using a micrometer and the mean values were calculated. The uniformity of the drug content of the films was determined, based on the drug weight ratios and the used polymers, by a spectrophotometric method.

\section{Drug release studies}

The dry films of known thickness were cut to a rectangular shape $\left(10 \mathrm{~cm}^{2}\right)$ using a glass template and fixed over a glass plate with silicon adhesive. The plate was immersed in a $200 \mathrm{ml}$ of citrate buffer solution $(\mathrm{pH}=5.0)$ maintained at a temperature of $37 \pm 1^{\circ}$. Then the 
paddle was adjusted at a distance of $2.5 \mathrm{~cm}$ from the surface of the glass plate and regulated to rotate at a speed of $60 \mathrm{rpm}$. Samples of $5 \mathrm{ml}$ each were withdrawn at predetermined time intervals and assayed spectrophotometrically at $\lambda_{\max }=310 \mathrm{~nm}$ for tetracaine $\mathrm{HCl}$. After each sampling, an equal volume of buffer citrate solution $(\mathrm{pH}=5.0)$ warmed to $37^{\circ}$ was added to the dissolution medium to maintain a constant volume. The experiment was done in triplicate and mean value was calculated. The release rate constant were calculated from linear plots of cumulative amount of drug released versus square root of time.

\section{Physicochemical characterization of tetracaine $\mathrm{HCl}$ eudragit films}

IR spectra, X-ray diffraction and DSC of tetracaine $\mathrm{HCl}$, Eudragit RS100, RL100 and drug loaded films were obtained to explore the possibility of interactions in drug-polymer systems.

In-vivo Evaluation (Local analgesic assay; Tail-Flick method)

The therapeutic potential of tetracaine $\mathrm{HCl}$ Eudragit polymeric film was evaluated using "Tail-Flick" method on a technoanalgiseometer model. For each experiment, a group of six wister rats was used. The mean body weight of the animals was $150 \mathrm{~g}$. In each experiment, solution of tetracaine $\mathrm{HCl}$ containing the same amount of the drug as a control was applied to the skin on an area approximately $1 \mathrm{~cm}^{2}$ and about $1.2 \mathrm{~cm}$ from the root. The tail of each rat was excited by radiant heat $\left(55 \pm 1^{\circ}\right)$ emitted by a hot nichrome wire. The nichrome wire was about $1 / 8$ inch below the tail. The reaction time required by the animal to Flick his tail has been recorded. Maximum current passed through the nichrome wire was in the range of 3-4 amps. The medicated films composed of Eudragit RS100: RL100 of a ratio (8:2) and (6:4) and plasticized with $20 \% \mathrm{w} / \mathrm{w}$ diethylphthalate were selected for in-vivo study because the other formulae were not flexible, not elastic and showed sticking to the casting mould during film preparation.

\section{Statistical analysis}

All the results obtained in the above experiments were checked for significancy by student's t-test, and a value of $\mathrm{P}<0.05$ was considered significant.

\section{RESULTS AND DISCUSSION}

\section{Effect of drug loading}

The casting solvent method used to prepare Eudragit RS100 films containing tetracaine $\mathrm{HCl}$ produced clear, colourless and homogenous films. There were no visible signs of drug crystallization up to $3.75 \% \mathrm{w} / \mathrm{w}$ of drug film. The cumulative amount of the drug released versus time for Eduragit RS100 films containing varying concentrations of tetracaine $\mathrm{HCl}$ was graphically illustrated in Fig. (1).

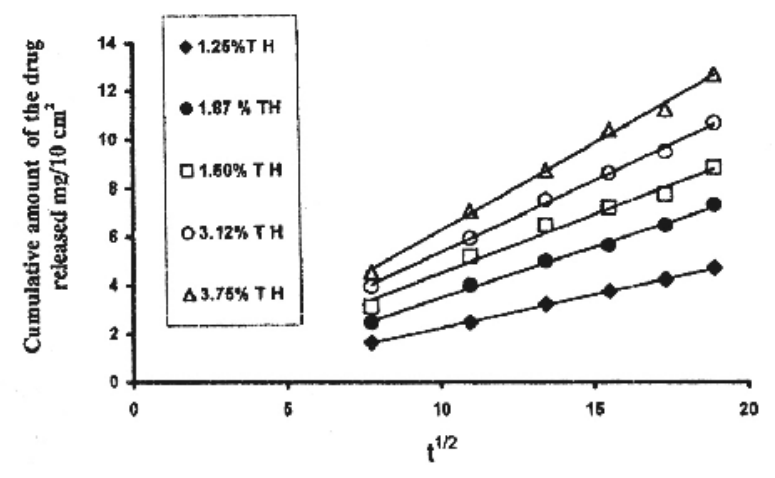

Fig. 1: Amount of drug released $\mathrm{mg} / 10 \mathrm{~cm}^{2}$ from films cmoposed of Eudragit RS100 at different concentrations of tetracaine hydrochloride.

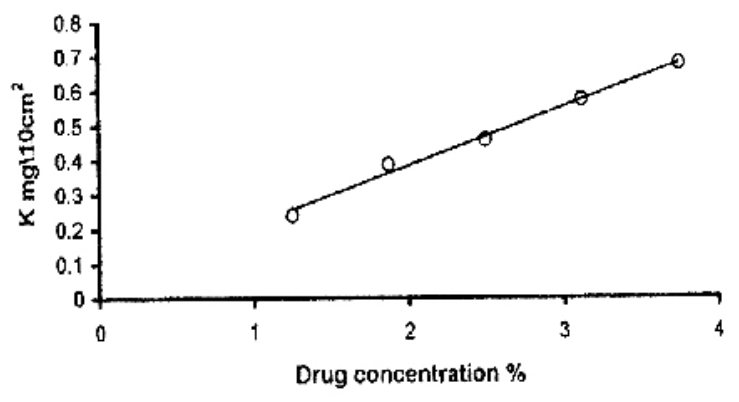

Fig. 2: Relationship of $\mathrm{K}$ (release rate constant) to percent of tetracaine hydrochloride for polymeric films composed of Eudragit RS100 and different drug concentrations.

Table (1) and Figure (2) describe the drug release from monolithic dispersions as there was a linear proportionality between the amount of drug released and the square root of time over almost the entire release curve. ${ }^{7}$ These linear plots appear to indicate that the drug release from these films is diffusion drug controlled. The release rate constant of the 
Table 1: Effect of drug concentrations on release rate constant $(\mathrm{k})$, half-life $\left(\mathrm{t}_{1 / 2}\right)$ for Eudragit RS100 films containing different concentrations of tetracaine hydrochloride according to Higuchidiffusion model.

\begin{tabular}{|c|c|c|c|}
\hline $\begin{array}{c}\text { Drug concentrations } \\
(\% \mathrm{w} / \mathrm{w} \text { of dry film })\end{array}$ & $\begin{array}{c}\text { Release rate constant }(\mathrm{k}) \\
\left(\mathrm{mg} / 10 \mathrm{~cm}^{2} / \mathrm{min}^{1 / 2}\right)\end{array}$ & $\begin{array}{c}\text { Correlation } \\
\text { coefficient }(\mathrm{r})\end{array}$ & $\mathrm{t}_{1 / 2}(\mathrm{~min})$. \\
\hline 1.25 & 0.272 & 0.999 & 337.91 \\
\hline 1.87 & 0.413 & 0.998 & 329.45 \\
\hline 2.5 & 0.485 & 0.992 & 425.124 \\
\hline 3.12 & 0.589 & 0.999 & 450.39 \\
\hline 3.75 & 0.712 & 0.998 & 443.48 \\
\hline
\end{tabular}

Table 2: Effect of Eudragit RS100:RL100 ratio on drug release rate constant $(\mathrm{k})$, half-life $\left(\mathrm{t}_{1 / 2}\right)$ for films containing $30 \mathrm{mg}$ tetracaine hydrochloride according to Higuchi-diffusion model.

\begin{tabular}{|c|c|c|c|c|c|}
\hline $\begin{array}{c}\text { ERS100: } \\
\text { ERL100 ratios }\end{array}$ & $\begin{array}{c}\text { Fraction of } \\
\text { ERL100 }\end{array}$ & $\begin{array}{c}\text { Release rate constant } \\
(\mathrm{k})\left(\mathrm{mg} / 10 \mathrm{~cm}^{2} / \mathrm{min}^{1 / 2}\right)\end{array}$ & $\log \mathrm{k}$ & $\begin{array}{c}\text { Correlation } \\
\text { coefficient }(\mathrm{r})\end{array}$ & $\mathrm{t}_{2}(\mathrm{~min})$. \\
\hline $10: 0$ & 0.00 & 0.7122 & -0.1472 & 0.998 & 443.35 \\
\hline $8: 2$ & 0.20 & 0.8273 & -0.0824 & 0.999 & 328.98 \\
\hline $6: 4$ & 0.40 & 0.9429 & -0.0255 & 0.999 & 253.07 \\
\hline $4: 6$ & 0.60 & 1.0883 & 0.0367 & 0.999 & 189.97 \\
\hline $2: 8$ & 0.80 & 1.0899 & 0.0373 & 0.992 & 189.41 \\
\hline $0: 10$ & 1.00 & 1.1891 & 0.0752 & 0.965 & 159.15 \\
\hline
\end{tabular}

Table 3: Effect of different plasticizers on release rate constant $(k)$, half-life $\left(t_{1 / 2}\right)$ for Eudragit RS100 films containing $30 \mathrm{mg}$ of tetracaine hydrochloride according to Higuchi-diffusion model.

\begin{tabular}{|c|c|c|c|}
\hline \hline Plasticizers & $\begin{array}{c}\text { Release rate constant }(\mathrm{k}) \\
\left(\mathrm{mg} / 10 \mathrm{~cm}^{2} / \mathrm{min}^{1 / 2}\right)\end{array}$ & $\begin{array}{c}\text { Correlation } \\
\text { coefficient }(\mathrm{r})\end{array}$ & $\mathrm{t}_{1 / 2}(\mathrm{~min})$. \\
\hline GTA & 1.289 & 0.999 & 135.41 \\
\hline PEG400 & 1.187 & 0.997 & 159.69 \\
\hline PG & 1.081 & 0.994 & 192.54 \\
\hline GTB & 1.061 & 0.999 & 199.87 \\
\hline DMPH & 1.010 & 0.999 & 220.56 \\
\hline DEPH & 0.983 & 0.999 & 232.84 \\
\hline
\end{tabular}

drug is proportional to the drug concentration. This could be explained by assuming that matrix porosity necessary for the diffusion pathways may be due to the pores created by the dispersed drug. Therefore, increasing drug concentration in the film would result in increasing the degree of internal porosity. This would consequently increase the film area exposed to the release medium. ${ }^{8,9}$

\section{Effect of polymeric ratio}

Table (2) showed an acceleration of the release rate constant and a decrease in $t^{1} / 2$. This can be ascribed to the high degree of hydration of the more hydrophilic polymer upon immersion of the films in the buffer. Increased porosity, hydrated channels formation and decreased tortuosity explain the greater hydration of Eudragit films containing higher ratios of the more hydrophilic polymer, RL100, 
which contain greater number of quaternary ammonium groups. The existance of a linearity with high correlation coefficient between the logarithmic value of release rate constant (log $\mathrm{K})$ and the fraction of the more hydrophilic polymer greatly confirms that the release of tetracaine $\mathrm{HCl}$ from Eudragit films follows Higuchi diffusion model. Similar results were obtained by Borodkin and Tucker ${ }^{10}$ who stated that there was a linear relationship between log $\mathrm{K}$ and fraction of hydroxypropylmethylcellulose (HPMC) in films composed of polyvinyl acetate / HPMC and containing either methapyrilene, salicylic acid or pentobarbital. The obtained results were illustrated in Table (2) and graphically presented in Figures (3) and (4).

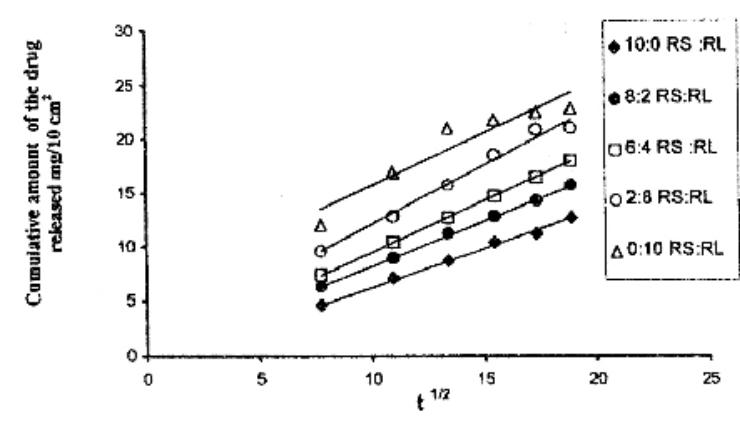

Fig. 3: Amount of drug released $\mathrm{mg} / 10 \mathrm{~cm}^{2}$ from Eudragit films each containing $30 \mathrm{mg} / \mathrm{film}$ tetracaine hydrochloride and different Eudragit RS100-RL100 ratios.

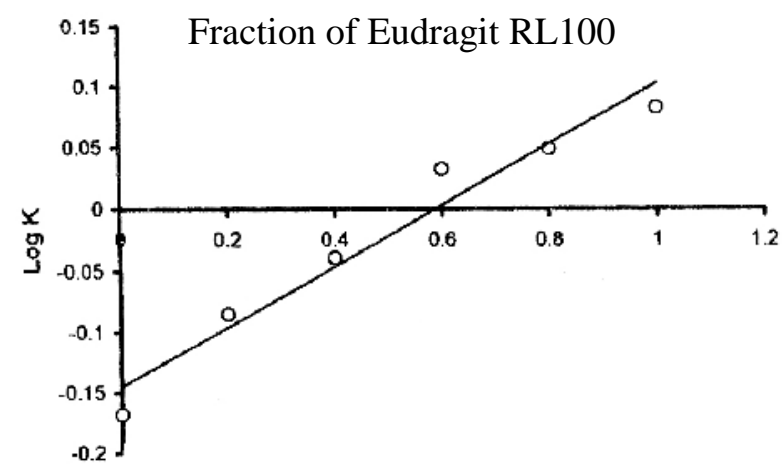

Fig. 4: Relationship of $\log K$ (release rate constant) to the fraction of Eudragit RL100 for films containing $30 \mathrm{mg}$ tetracaine hydrochloride and different Eudragit RS100-RL100 ratios.

\section{Effect of plasticizer}

Two proposed factors could be taken into consideration to explain the effect of plasticizer content on the drug release profile. The first is that the plasticizer may decrease the degree of compactness of the polymeric matrix due to bonding to the polymeric molecules and forming pores through which the drug leaches out. The second factor is the solubility of the plasticizer in water through hydrogen bonding leading to an increase in the hydrophilic properties of the matrices and formation of hydrated channels. This may explain the higher effect of the water soluble plasticizers (GTA \& PEG400 and PG) on the drug release rate from Eudragit RS100 polymeric matrix as compared with GTB, DMPH and DEPH which were used as a water-insoluble plasticizers. Table (3) and Figure (5) show the effect of different types of plasticizers on the release profile of tetracaine $\mathrm{HCl}$ from Eudragit RS100 polymeric films. The effect of plasticizers on the release profile of the drug could be arranged as follows: GTA > PEG400 > PG > GTB > DMPH > DEPH.

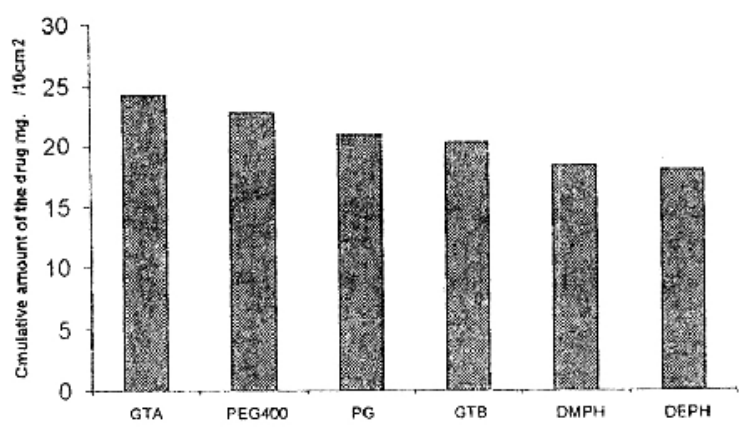

Fig. 5: Comparison of drug reelase profile for Eudragit RS100 films each containing 30 $\mathrm{mg}$ tetracaine hydrochloride nd plasticized with $20 \% \mathrm{w} / \mathrm{w}$ of polymer with different plasticizers.

Upon diffusion of the buffer inside the film, tetracaine $\mathrm{HCl}$ would diffuse through the hydrated voids created by those water-insoluble plasticizers. This may explain the smaller amount of drug released from Eudragit RS100 films plasticized wither GTB, DMPH or DEPH. Similar results were obtained by Salama et al., ${ }^{11}$ who studied the chlorphenesin release from Eudragit films containing different types of plasticizers. 


\section{Physicochemical characterization of tetracaine $\mathrm{HCl}$ eudragit films \\ IR studies}

Fig. (6) shows the absence of changes in the location or width of characteristic infrared absorption bands of the drug in either physical mixture or cast film. These results agree with Jenquin and McGinity ${ }^{6}$ who studied the interaction between acidic drugs and Eudragit RL and RS polymers.

\section{Differential scanning calorimetry DSC}

The DSC charts showed the absence of drug endothermic peak in the cast film with the Eudragit polymers at different ratios, while the peak still appears in the physical mixture. The disappearance of endothermic peak was attributed to the existence of the drug in the amorphous form in the cast film (concentration of the drug was $3.75 \% \mathrm{w} / \mathrm{w}$ of polymer) with different ratios of polymer, (Fig. 7). (a)

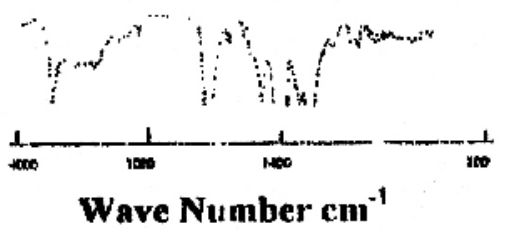

(b)

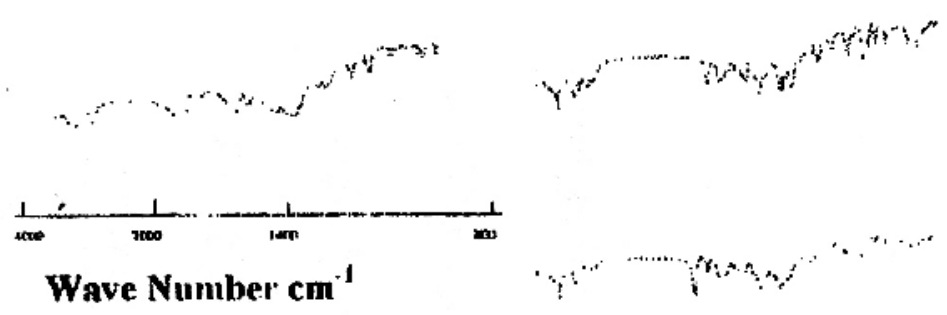

(c)

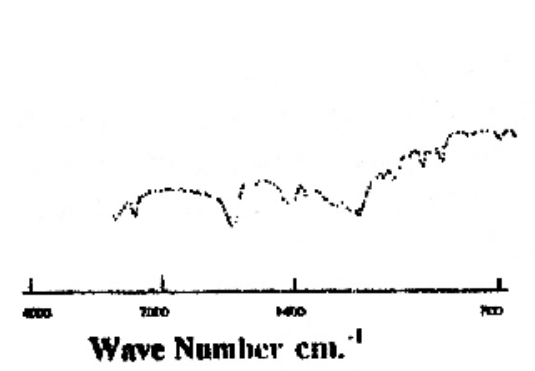

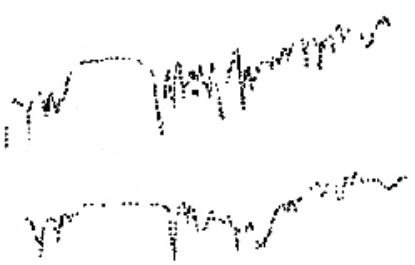

(1)

(2)

(3)

(4)

(5)

(6)

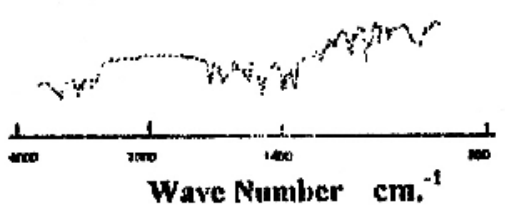

(e)
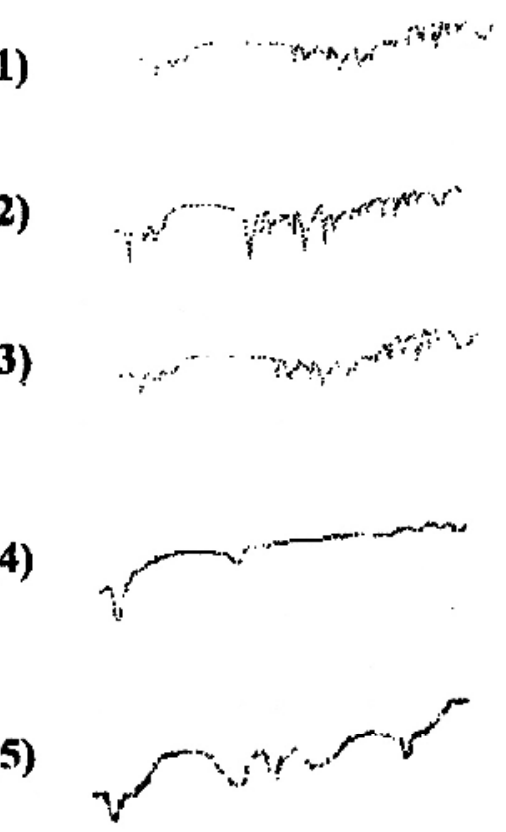

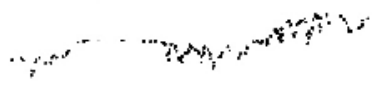

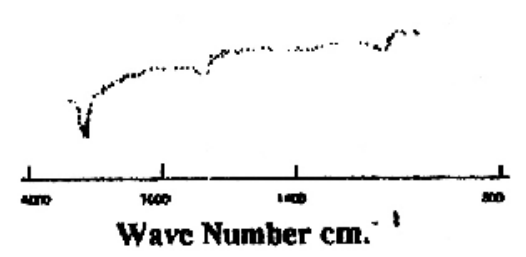

Fig. 6: IR spectra of powder of:
(a) Tetracanie hydrochloride (T.H)
(b) Eudragit RL100
(c) Eudragit RS100
(d) TH-Eud. RL100 - Eud. RS100 physical mixtures
(e) TH-Eud. RL100 - Eud. RS100 films. T.H components are $3.75 \%$ in both (d) \& (e)
Ratio of Eudragit RL100 / Eud. RS100 are (1) 10/0
(2) $8 / 2$
(3) $6 / 4$
(4) $4 / 6$
(5) $2 / 8$
(6) $0 / 10$ 
(a)
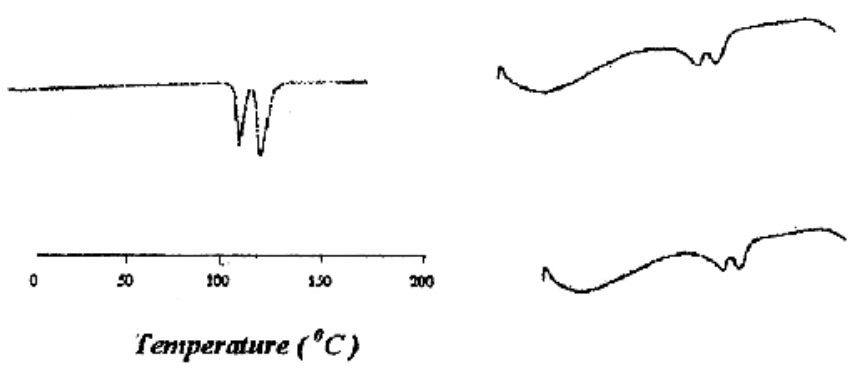

(2)

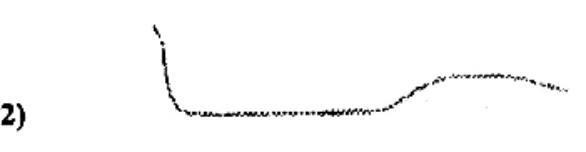

(b)

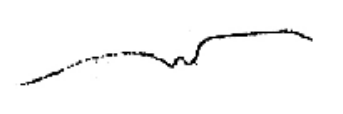

(3)

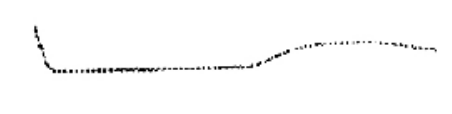

(4)

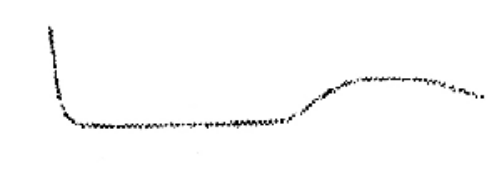

(5)
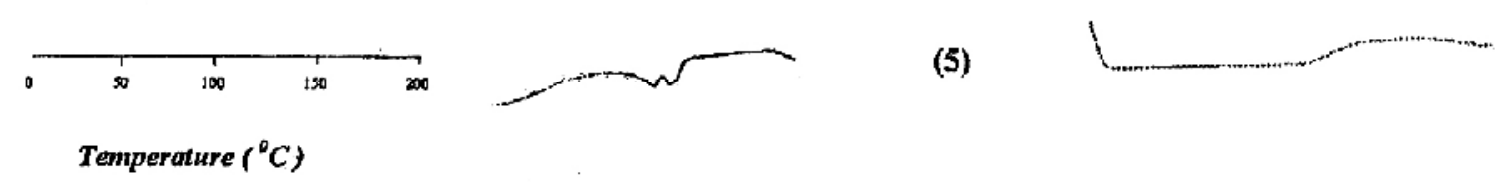

(c)
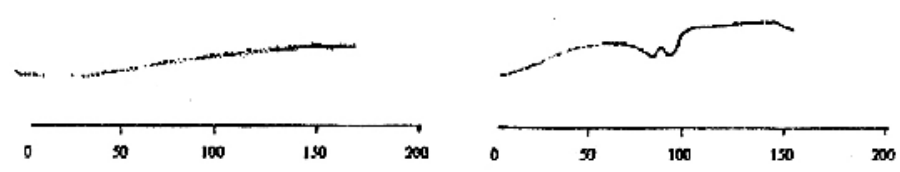

(6)

Temperature $\left({ }^{\circ} \mathrm{C}\right)$

(e)

(1)

(3)

Temperature $\left({ }^{\circ} \mathrm{C}\right)$

Fig. 7: Differential scanning calorimetry charts of powder of:
(a) Tetracanie hydrochloride (T.H)
(b) Eudragit RL100
(c) Eudragit RS100
(d) TH-Eud. RL100 - Eud. RS100 physical mixtures
(e) TH-Eud. RL100 - Eud. RS100 films. T.H components are $3.75 \%$ in both (d) \& (e)
Ratio of Eudragit RL100 / Eud. RS100 are
(1) $10 / 0$
(2) $8 / 2$
(3) $6 / 4$
(4) $4 / 6$
(5) $2 / 8$
(6) $0 / 10$

\section{X-ray diffractometry}

Fig. (8) showed that, tetracaine $\mathrm{HCl}$ crystalline peaks were not observed in the cast film in spite of their appearance in the physical mixture. This was attributed to the complete conversion of the drug from crystalline state to the amorphous state. These results are in agreement with Kohda et al. ${ }^{12}$ who reported the disappearance of the X-ray diffraction peaks of the drug crystal in the lidocaine HCl-EC-HPC solid dispersion film. 


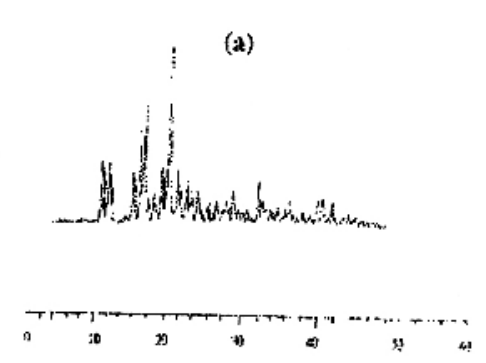

20

(b)

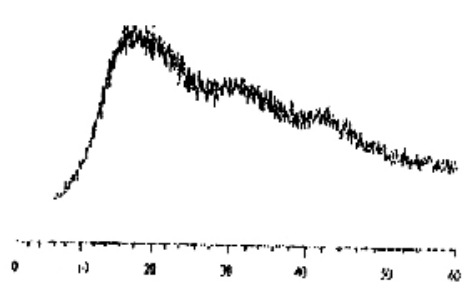

$2 \theta$
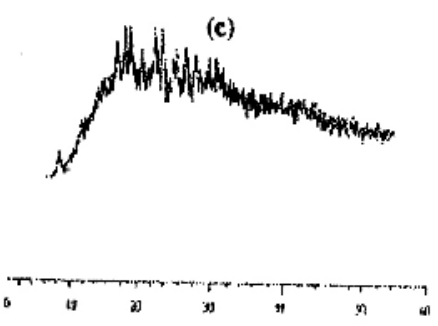

$2 \theta$ (d)
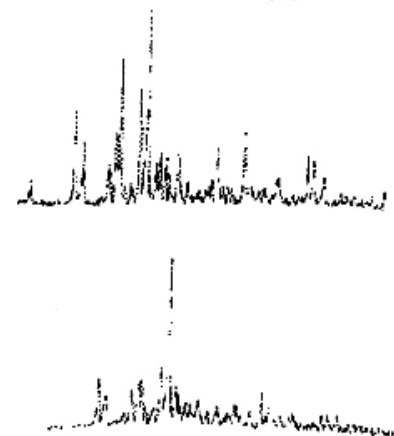

(2)

(1)
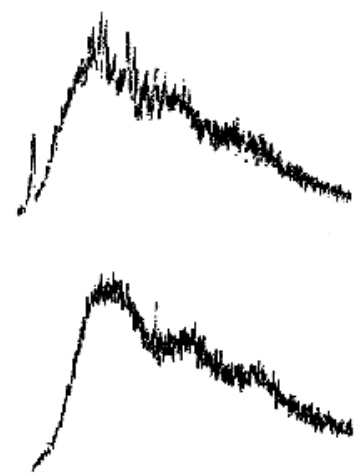

(3)
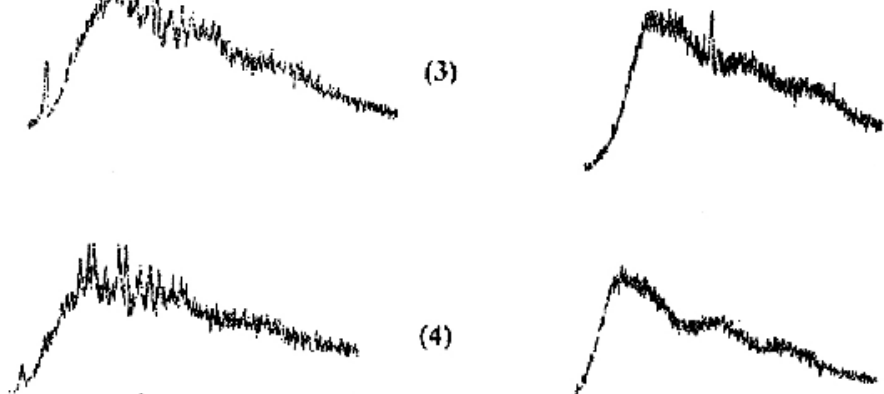

(4)
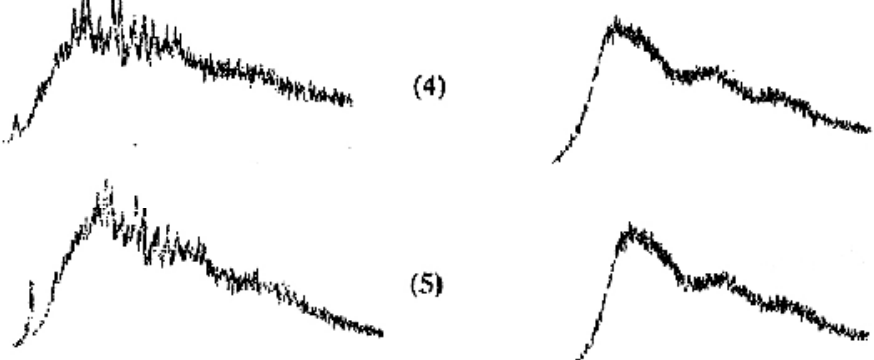

(5)
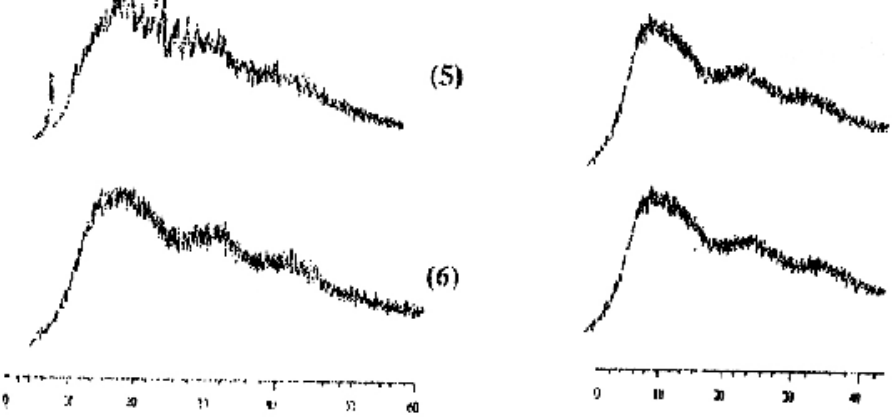

26

Fig. 8: X-ray diffraction pattern of powder of:
(a) Tetracanie hydrochloride (T.H)
(b) Eudragit RL100
(c) Eudragit RS100
(d) TH-Eud. RL100 - Eud. RS100 physical mixtures
(e) TH-Eud. RL100 - Eud. RS100 films. T.H components are $3.75 \%$ in both (d) \& (e)
Ratio of Eudragit RL100 / Eud. RS100 are
(1) $10 / 0$
(2) $8 / 2$
(3) $6 / 4$
(4) $4 / 6$
(5) $2 / 8$
(6) $0 / 10$

\section{In-vivo evaluation of tetracaine $\mathrm{HCl}$ polymeric films}

The increase in the response after applying tetracaine HCL film was considered as an analgesic response of the drug. The mean local response time of tetracaine $\mathrm{HCl}$ polymeric film is shown in Fig. (9).
The heat sensitive response of an untreated tail was in the range $25 \pm 5 \mathrm{sec}$. The obtained results showed the analgesic response time of a topically applied aqueous solution of tetracaine $\mathrm{HCl}$ that was considered as a control, while the other three columns represent cream and film containing tetracaine $\mathrm{HCl}$. 


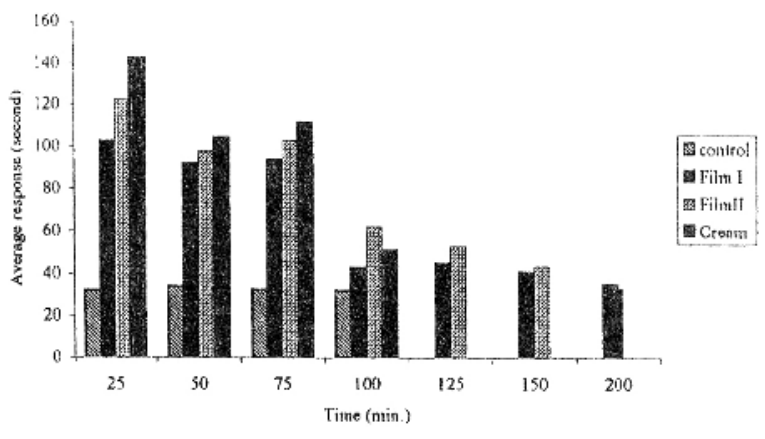

Fig. 9: Analgesic action of topically applied tetracaine hydrochloride polymeric films.

Maximum effect was attained after $20 \mathrm{~min}$ of the application then reduced gradually. However, a marked anesthetic effect is noticeable even after $180 \mathrm{~min}$ of the application of Eudragit polymeric film containing tetracaine $\mathrm{HCl}$ when compared with control. The anaglesic response of an aqueous solution of tetracaine $\mathrm{HCl}$ was in the range 30$35 \mathrm{sec}$, and increased up to $140-145 \mathrm{sec}$. for cream. It was clear that tetracaine $\mathrm{HCl}$ cream gave maximum analgesic response but reduced after few minutes. While tetracaine $\mathrm{HCl}$ Eudragit film composed of Eudragit RS: Eudragit RL of a ratio (8:2) and plasticized with $20 \% \mathrm{w} / \mathrm{w}$ diethylphthalate gave long range of analagesic response. Thus, this study demonstrated the potential application of Eudragit polymeric films in both controlled drug delivery systems and in the formulation of tetracaine $\mathrm{HCl}$ topical films.

\section{REFERENCES}

1- K. Lehmann, Chemistry and application properties of polymethylacrylate coating systems. In McGinity, J. W. (Ed.), Aqueous Polymeric Coatings for Pharmaceutical Applications, Marcel Dekker, New York, 1989, pp. 153-245.

2- S. S. Tambhekar, P. J. Green and Y. Rojanasakul, Drug Dev. Ind. Pharm., 7, 2789 (1987).

3- R. Bodmeier and O. Paeratakul, Int. J. Pharm., 59, 197 (1990).

4- R. S. Okor and C. E. Obi, Int. J. Pharm., 58, 89 (1990).

5- S. R. Jenquin, S. M. Liebowitz and R. E. Sarabia, J. Pharm. Sci., 79 (9), 811 (1990).

6- M. R. Jenquin and J. W. McGinity, Int. J. Pharm., 101, 23 (1994).

7- Y. Shamuelov, M. Donbrow and M. Friedman, J. Pharm. Sci., 68, 3 (1979).

8- H. Lapidus and N. G. Lordi, J. Pharm. Sci., 55, 810 (1966).

9- H. Lapidus and N. G. Lordi, J. Pharm. Sci., 57, 1292 (1968).

10- S. Borodkin and F. E. Tucker, J. Pharm. Sci., 63, 9 (1979).

11- M. Salama, F. Ghazy, A. Bosela and A. Ismail, Alex. J. Pharm. Sci., 11 (2), 59 (1997).

12- Y. Kohada, H. Kobayashi, Babayas, H. Yuasa, Int. J. Pharm., 158, 147-155 (1997). 